\title{
Bronchial responsiveness in an area of air pollution resulting from wire reclamation
}

\author{
J Y Wang, T R Hsiue, H I Chen
}

\begin{abstract}
Spirometric data from 86 primary school children living in an area of air pollution resulting from wire reclamation incineration were analysed and compared with 92 nonexposed schoolchildren. There were lower values for forced vital capacity and forced expiratory volume and thus a higher incidence of pulmonary function abnormalities in the children in the polluted area than those in a non-polluted area. There was no significant difference in the prevalence of respiratory symptoms between these two areas when surveyed by a questionnaire. Twenty eight schoolchildren from a non-polluted area and 26 children from the polluted area, who were said to have no respiratory symptoms and for whom consent forms were obtained, were recruited for a bronchial responsiveness test. Nine (35\%) of 26 children in the polluted area were responders ( $<50 \mathrm{U}$ ) and only one of the control subjects was a responder. The mean (SD) log cumulative dose producing a $35 \%$ decrease in respiratory conductance and the minimum cumulative dose required to decrease respiratory conductance from the baseline in the children of the polluted area were significantly lower than that of the control subjects $(1.32(0.37) \log$ units and $1.26(0.44) \log$ units, respectively, compared with $1.70(0 \cdot 10) \mathrm{log}$ unit for both measurements in non-exposed children). These results indicate that air pollution resulting from wire reclamation can produce a detrimental effect on both pulmonary function and bronchial responsiveness in primary schoolchildren who are continually exposed to air pollutants from the time of their birth.
\end{abstract}

National Cheng-Kung University Medical

College, Taiwan, Department of Paediatrics J Y Wang

Department of Internal Medicine

T R Hsiue

Department of Physiology H I Chen

Correspondence to: Dr Jiu-Yao Wang, Department of Paediatrics, College of Medicine, National Cheng-Kun University, No. 138 , Sheng-Li Road, Tainan, 70428 Taiwan, Republic of China.

Accepted 12 November 1991
Wire reclamation incineration is a source of environmental contamination. The resulting air pollutants include suspended particulates, nitrogen dioxide, sulphur dioxide, heavy metals, polycyclic aromatic hydrocarbons, polychlorinated biphenyls, polychlorinated dibenzofurans, and dioxins. ${ }^{1-3}$ These pollutants cause damage in the hepatic, dermatological, and immunological systems and may also cause fetal death. ${ }^{45}$ In Taiwan, heavy metals are recovered for reuse by wire reclamation incineration. Wires were incinerated in an open area without using any pollution control equipment. The reclamation process has been performed for about 20 years in Wanli, a severely polluted area located in the southern part of Taiwan. Several years ago, the Bureau of Environmental Protection of Taiwan detected significant concentrations of dioxins and polychlorinated dibenzofurans in the air and soil of this area. ${ }^{1}$ According to the governmental reports, there were also high morbidity and mortality rates due to chronic pulmonary disease in the Wanli area. ${ }^{1}$ Previously, we found that the incidence of pulmonary function abnormality in children of the polluted areas was greater than that of the non-polluted area. ${ }^{6}$ In order to investigate if long term exposure to air pollution resulting from wire reclamation incineration might have harmful effects on the airway reactivity, we compared the bronchial responsiveness of primary schoolchildren in the polluted area to those living in a non-polluted area.

\section{Methods}

Children in the primary school in the polluted area of Wanli, near the incineration site, and in one school in a non-polluted area located in the centre of Tainan city were chosen for this cross sectional study. All children had been inhabitants in these districts since their birth, and their socioeconomic background was similar. By using a stratified and systematic sampling method, 100 sixth grade (12 year old) primary schoolchildren in these two areas were selected as subjects for study during April and June.

In addition to the air quality information provided by the Bureau of Environmental Protection of Taiwan, environmental air quality was evaluated by the concentrations of suspended particulates, nitrogen dioxide, and sulphur dioxide, of the air sampled from the two areas under study. The air sample for determining suspended particulates ${ }^{7}$ was collected as previously described. ${ }^{6}$

All pulmonary function tests were administered in the schools by trained technicians using a portable spirometer (Microspiro-298, Chest). The procedure for performing forced spirometry was the same as our previous report. ${ }^{6}$ The values of forced vital capacity (FVC), forced expiratory volume in one second $\left(\mathrm{FEV}_{1}\right)$, and forced expiratory flow between $25 \%$ and $75 \%$ of the forced vital capacity $\left(\mathrm{FEV}_{25-75}\right)$ were expressed as percentage of predicted values calculated by the equations of Polgar and Promadhat. ${ }^{8}$ Abnormal spirometric parameters were defined as (a) FVC or $\mathrm{FEV}_{1}$ of less than $80 \%$ of predicted values or (b) a ratio of $\mathrm{FEV}_{1}: \mathrm{FVC}$ less than $75 \%$.

A modified version of the ATS-DLD-78-C questionnaire ${ }^{9}$ concerning the anthropometric data, socioeconomic condition, smoking history of the parents, and respiratory symptoms of the children was translated into Chinese and 
answered by the parents during home visits by trained personnel. Socioeconomic status (SES), derived from parents' occupation and education, ${ }^{10}$ was divided into low (V and IV), middle (III), and high (II and I) categories. Chronic cough was considered to exist when a child frequently coughed for more than two years without apparent association with a common cold. Wheezing was considered to be present when it occurred with or without a common cold.

Because the inhabitants might fear that the government would prohibit wire reclamation incineration (one of their major sources of income) if the survey revealed unfavourable results, a bias in the parents' answers to the questionnare existed. So only those who replied that their children had no respiratory symptoms who completed consent forms had their children chosen for methacholine inhalation tests. Twenty eight schoolchildren from a non-polluted area and 26 children from polluted area were recruited from the study population for bronchial responsiveness evaluation.

Methacholine inhalation tests were carried out with an Astograph (TCK-6100, Chest) as previously described. ${ }^{11}$ This machine can write dose response curves of respiratory resistance (Rrs) with tidal breathing during continuous inhalation of methacholine in twofold increment concentrations from 0.049 to $25 \mathrm{mg} / \mathrm{ml}$ every minute. Three indices were evaluated for the airway responsiveness in the present study: the baseline value of Rrs (Rrs-cont); the minimum cumulative dose required to start to decrease respiratory conductance from the baseline $\left(D_{\min }\right)$; and the cumulative dose producing a $35 \%$ decrease in respiratory conductance ( $\mathrm{PD}_{35} \mathrm{Grs}$ ).

Results are presented as mean (SD) values. Statistical evaluations were performed by Student's $t$ test. A p value below 0.05 was considered significant. Differences in prevalence of pulmonary function abnormalities and respiratory symptoms between these two groups were evaluated by $\chi^{2}$ test. Statistical analyses of $\mathrm{PD}_{35} \mathrm{Grs}$ and $\mathrm{D}_{\min }$ values were performed on
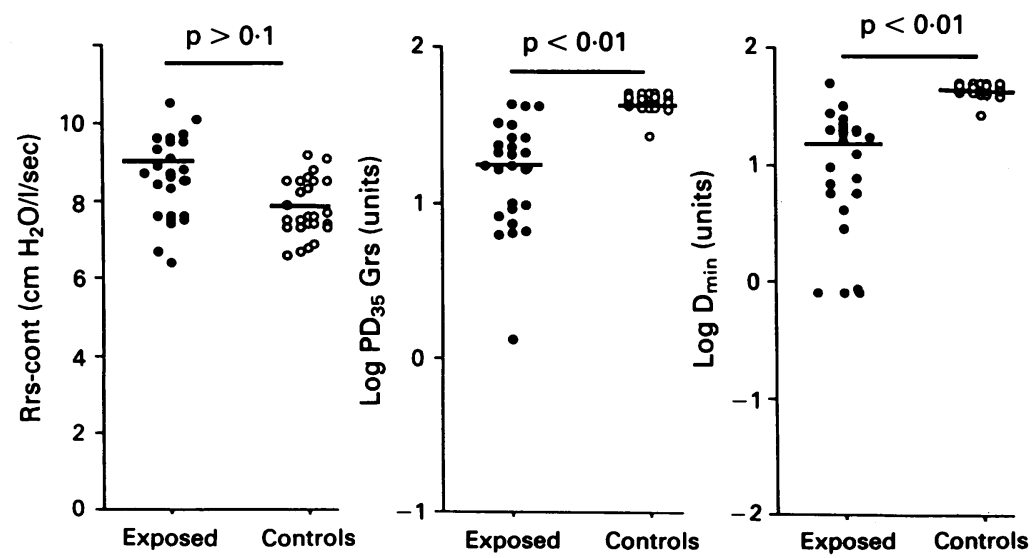

Baseline respiratory resistance (Rrs-cont), bronchial reactivity $\left(P D_{35} G r s\right)$, and bronchial sensitivity $\left(D_{\text {min }}\right)$ in 26 children from the exposed area (solid circles) and 28 control subjects (open circles). A bar shows the mean value. Values of $P D_{35} G r s$ and $D_{\min }$ of more than $50 U$ were plotted as $50 U\left(\log P D_{35} G r s\right.$ and $\log D_{\min }$ of 1.699$)$, and represent the non-responders whose respiratory resistance did not change throughout the methacholine inhalation test. logarithmically transformed data because they showed logarithmic normal distribution. ${ }^{12}$

\section{Results}

In our study we found the polluted area had higher concentrations of sulphur dioxide and nitrogen dioxide than the non-polluted area which served as a control (sulphur dioxide 18.1 $v 2 \cdot 1$ parts/billion (ppb); nitrogen dioxide $12 \cdot 6 v$ $2 \cdot 1 \mathrm{ppb})$.

Questionnaires were returned and spirometry was successfully performed by 86 children in the exposed area and 92 in the control area. Twenty two children were excluded because of grossly incomplete questionnaires and unacceptable spirometry. There were no significant differences in demographic characteristics between these two areas (table). In addition, no significant differences in the prevalence of respiratory symptoms surveyed by questionnaire between the polluted and non-polluted areas were noticed.

The distributions of pulmonary function abnormalities in the polluted group were $15 \cdot 6 \%$ for $\mathrm{FVC}, 17 \cdot 5 \%$ for $\mathrm{FEV}_{1}$. In the control group, the distributions of abnormality were $6.5 \%$ for FVC, $3 \cdot 2 \%$ for $\mathrm{FEV}_{1}$. The incidence of pulmonary function abnormality in the polluted area was thus greater than that of the nonpolluted area $\left(\mathrm{p}<0.05, \chi^{2}\right.$ test $)$. These results were the same as in our previous report.

The results of methacholine inhalation test are shown in the figure: baseline airway resistance (Rrs-cont), bronchial reactivity $\left(\mathrm{PD}_{35} \mathrm{Grs}\right)$, and bronchial sensitivity $\left(D_{\min }\right)$. There was no statistical difference in Rrs-cont between these two groups. Takishima et $a l^{12}$ defined the subjects who had a $D_{\min }$ of more than $50 \mathrm{U}$ (or $\log D_{\min }>1.699 \log$ unit) as non-responders and the subjects who had a $D_{\min }$ of less than 50 $\mathrm{U}$ as responders. According to their criteria, nine $(35 \%)$ of 26 children living in the polluted area were responders and only one of 28 children from the non-polluted area subjects was a responder. The mean (SD) $\log \mathrm{PD}_{35} \mathrm{Grs}$ of the children of the polluted area was significantly lower than that of the non-polluted area $(1.32(0.37) \log$ units and $1 \cdot 70(0 \cdot 10) \log$ units, respectively $\mathrm{p}<0.01)$. The mean (SD) $\log \mathrm{D}_{\min }$ of the children of the polluted area was significantly lower than that of the control subjects

Demographic characteristics of the study children in polluted and non-polluted areas

\begin{tabular}{lll}
\hline & Polluted area & Non-polluted area \\
\hline Sex: M/F & $46 / 40$ & $50 / 42$ \\
Height (cm): M/F & $133 \cdot 5 / 135 \cdot 6$ & $132 \cdot 7 / 134 \cdot 9$ \\
Weight (kg): M/F & $29 \cdot 8 / 31 \cdot 2$ & $30 \cdot 1 / 31 \cdot 6$ \\
SES (\%) & & \\
I & $3 \cdot 0$ & $3 \cdot 1$ \\
II & $18 \cdot 2$ & $25 \cdot 2$ \\
III & $69 \cdot 4$ & $68 \cdot 4$ \\
IV & $9 \cdot 4$ & $3 \cdot 3$ \\
Parents smoking (\%): & $33 \cdot 6$ & $31 \cdot 5$ \\
Father & 0 & 0 \\
Mother & $4 \cdot 7$ & $6 \cdot 5$ \\
Chronic cough & $3 \cdot 5$ & $4 \cdot 3$ \\
Chronic phlegm & $2 \cdot 3$ & $3 \cdot 3$ \\
Wheezing & $2 \cdot 3$ & $3 \cdot 3$ \\
Diagnosed asthma & $\mathbf{8} \cdot 1$ & $6 \cdot 5$ \\
Chest illness & & \\
\hline
\end{tabular}

*SES (socioeconomic status) derived from parents' occupation and education was divided into low (V and IV), middle (III), and high (II and I) categories. 
$(1 \cdot 26(0 \cdot 44) \log$ units and $1 \cdot 70(0 \cdot 10) \log$ units respectively, $\mathrm{p}<0.01)$.

\section{Discussion}

This study examined the bronchial responsiveness and pulmonary function of primary schoolchildren exposed to wire reclamation incineration. It is known that this industry is a source of environmental contamination. In our study, all the children in polluted areas have suffered from long term exposure to air pollution caused by outdoor wire reclamation incineration since their birth. Our results showed that children in the exposed area had a greater incidence of pulmonary function abnormality than the control children, both in the restrictive and obstructive types of abnormality. Moreover, we also found that the bronchial responsiveness was increased in children living in the exposed area compared with those of the controls (figure). This suggests that air pollutants resulting from wire reclamation incineration have an ill effect on pulmonary function in children.

Although the polluted area had higher concentrations of sulphur dioxide and nitrogen dioxide than the non-polluted area, we did not measure the levels of exposure to pollutants ascribable to the process of wire reclamation incineration due to the lack of equipment for these measurements. Nonetheless, the Bureau of Environmental Protection of Taiwan reported several years ago that wire reclamation incineration produced a lot of air pollutants, ${ }^{1}$ including highly toxic substances such as polycyclic aromatic hydrocarbons, dioxins, and polychlorinated dibenzofurans in Wanli and its vicinity. Therefore, the impairment of pulmonary functions and an increase in bronchial hyper-responsiveness in exposed children might be due to the effect of air pollution resulting from wire reclamation incineration.

An analysis of epidemiological as well as animal studies leaves little doubt that air pollution aggravates respiratory problems. Atmospheric pollution by smoke, sulphur dioxide, and nitrogen dioxide may provoke progressive impairment of ventilatory function and airflow obstruction in control subjects and in asthmatic patients. ${ }^{13}$ The effect of long term exposure to low or moderate concentrations of air pollutants has not been defined. Tseng and $\mathrm{Li}$ found that prolonged exposure to low concentrations of atmospheric sulphur dioxide might induce airway inflammation and bronchial hyper-reactivity and predispose to episodes of childhood asthma. ${ }^{14}$ Sultz et al reported a significant correlation between levels of air pollution and the number of children hospitalised for asthma in Buffalo. ${ }^{15}$ By contrast, Ware et $a l^{16}$ reported that, for preadolescent children, exposure to moderately increased concentrations of pollutants-for example, from coal burningwould increase the risk of bronchitis and of other respiratory disorders, but has little or no effect on pulmonary function level. These studies suggest that long term exposure to air pollution might have a harmful effect on pulmonary function in children or asthmatic patients.
Our results were consistent with our previous report ${ }^{6}$ that there were no significant differences in the prevalence of chronic cough and wheezing. These results seemed to contradict the pulmonary function measurements. The possible explanation was the bias in answering the questionnaire due to the fear that the government would prohibit wire reclamation (a major employer) if the surveys revealed unfavourable results. The epidemiological approach to survey respiratory symptoms by questionnaire was somewhat crude. The major obstacle in investigations of this nature lies in the fact that morbidity and pollution data are usually held by local government officials in diverse disciplines. A complete environmental analysis and health prevalence study could meet with further resistance from the industry, economists, and local politicians. ${ }^{17}$ Our results on bronchial responsiveness might provide further evidence of the impairment in pulmonary health in the children of the polluted area.

In conclusion, our results showed that air pollution resulting from wire reclamation incineration could produce a detrimental effect on both pulmonary function and bronchial responsiveness in primary schoolchildren who had been chronically exposed to the air pollutants since their birth.

1 Bureau of Environmental Protection of Taiwan. The effect of air pollution on human health in Wanli and Chiading areas. Taipei: Bureau of Environmental protection of Taiwan, 1986. (BEP 73-05-004, 73-05-009, 74-05-007.)

2 Buser HR. Formation of polychlorinated dibenzofurans (PCDFs) and dibenzo-p-dioxins (PCDDs) from the pyrolysis of chlorobenzenes. Chemosphere 1979;6:415-24

3 Hryhorezuk DO, Withrow WA, Hesse CS, Beasley VR. A wire reclamation incinerator as a source of environmental wire reclamation incinerator as a source of environmental contamination with tetrachlorodibenzo-p-dioxins and tetra-
chlorodibenzofurans. Arch Environ Health 1981;36:228-34.

4 Chen HS. Polychlorinated biphenyls: environmental occurrence, biological and toxtology effects. Clin Med 1981;7 4-8

5 Pocchiari F, Silano V, Zampieri A. Human health effects from accidental release of TCCD at Seveso, Italy. In Nicholson WJ, Moore JA, eds. Health effects of halogenated aromatic hydrocarbons. Ann NY Acad Sci 1979;320: 257-70.

6 Hsiue TR, Lee SS, Chen HI. Effects of air pollution resulting wire reclamation incineration on pulmonary function in children. Chest 1991;100:698-702.

7 Environmental Protection Agency. Methods of air sampling and analysis. Washington DC: American Public Health Association, 1972.

8 Polgar G, Promadhat V. Pulmonary function testing in children techniques and standards. Philadelphia: WB Saunders, 1971 . 9 Comstock GW, Tockman MS, Helsing KJ, Hennesy KM Standardized respiratory questionnaires: comparison of the old and new. Am Rev Respir Dis 1979;119:45-53.

10 Schenker MB, Samet JM, Speizer FE. Risk factors for childhood respiratory disease: the effect of host actors and home environmental exposures. Am Rev Respir Dis 1983 128: $1038-43$.

11 Wang JY. The study of bronchial responsiveness in asthmatic children by forced oscillation technique. Asian Pac $\mathcal{J}$ Allergy Clin Immunol 1991;9:51-6.

12 Takishima T, Hida W, Sasaki H, Suzuki S, Sasaki T. Directwriting recorder of the dose response curve of the airway to methacholine: clinical application. Chest 1981;80:600-6.

13 Avol EL, Linn Ws. Shamod DA. Respiratory responses to young asthmatic volunteers in controlled exposures to sulfuric acid aerosol. Am Rev Respir Dis 1990;142:343-8.

14 Tseng RYM, Li CK. Low level atmospheric sulfur dioxide pollution and childhood asthma. Ann Allergy 1990;65: 379-83.

15 Sultz H, Feldman JG, Schlesinger ER, Mosher EM. An effect of continued exposure to air pollution on the incidence of chronic childhood allergy disease. Am $\mathcal{f}$ Public Health 1970;60:891 child

16 Ware JH, Ferris BG Jr, Dockery DW, Spengler JD, Stram DO, Speizer FE. Effects of ambient sulfur oxides and DO, Speizer FE. Effects of ambient sulfur oxides and suspended particles on respiratory health of preado
children. Am Rev Respir Dis 1986;133:834 42.

17 Anonymous. Environmental and the public's purses [Editorial]. Nature 1988;333:381. 